\title{
Real-Time Monitoring of Atmospheric Magnesium Alloy Corrosion
}

\author{
M. Strebl ${ }^{*} *$ and S. Virtanen ${ }^{* * *, z}$ \\ Department of Materials Science (LKO, WW-4), University of Erlangen-Nuremberg, 91058 Erlangen, Germany
}

\begin{abstract}
The atmospheric corrosion progress of Mg alloys is traditionally tracked by determining mass loss of the samples after exposure. This method provides only an average corrosion rate over the exposure time and is destructive. The work presented introduces a new non-destructive method for real-time monitoring of atmospheric $\mathrm{Mg}$ alloy corrosion rates based on the evolved hydrogen gas. This is realized with an adaption of the gravimetric hydrogen collection method. The effect of temperature and atmospheric pressure variations during the experiment can be compensated and reliable atmospheric hydrogen evolution rates can be measured. The new technique was applied to monitor real-time atmospheric corrosion rates of $\mathrm{Mg}$ alloys $\mathrm{AZ3} 1$ and $\mathrm{AZ} 91$ with different amounts of $\mathrm{NaCl}$ contamination. Comparing the results of the gravimetric hydrogen method with mass loss experiments reveals a good correlation of the consumed charge over the total exposure time, thus validating the new technique. Evidence for the contribution of $\mathrm{O}_{2}$ reduction reaction to cathodic processes on $\mathrm{Mg}$ alloy atmospheric corrosion is presented.

(c) The Author(s) 2018. Published by ECS. This is an open access article distributed under the terms of the Creative Commons Attribution Non-Commercial No Derivatives 4.0 License (CC BY-NC-ND, http://creativecommons.org/licenses/by-nc-nd/4.0/), which permits non-commercial reuse, distribution, and reproduction in any medium, provided the original work is not changed in any way and is properly cited. For permission for commercial reuse, please email: oa @electrochem.org. [DOI: 10.1149/2.0011911jes]
\end{abstract}

(cc) BY-NC-ND

Manuscript submitted October 10, 2018; revised manuscript received November 27, 2018. Published December 12, 2018. This paper is part of the JES Focus Issue on Advanced Techniques in Corrosion Science in Memory of Hugh Isaacs.

Magnesium $(\mathrm{Mg})$ alloys are attractive lightweight materials for automotive applications due to their high specific strength. However, a more widespread use of $\mathrm{Mg}$ alloy components is hindered by their corrosion properties, and there is a high demand for the development of protective coatings, inhibitors, and more corrosion resistant alloys. To compare the corrosion performance of new Mg technology and to understand the mechanisms that govern $\mathrm{Mg}$ corrosion, it is important to employ suitable test methods to measure corrosion rates. Full immersion conditions are frequently used to study the corrosion behavior, although $\mathrm{Mg}$ alloys are typically subjected to atmospheric corrosion environments in most real world applications. With a limited amount of electrolyte during atmospheric corrosion, the corrosion mechanism can change compared to the immersion scenario. Esmaily et al. ${ }^{1}$ provide an overview of the differences between both corrosion environments. For example, corrosion products that partly dissolve in a bulk electrolyte can remain on the surface and block active sites in the case of atmospheric conditions. ${ }^{2}$ The rise in $\mathrm{pH}$ due to the cathodic reaction can be less pronounced in immersion tests than in the limited amount of electrolyte on the surface under atmospheric exposure. Effects of micro-galvanic coupling of secondary phases can be reduced with thin electrolyte films. ${ }^{3}$ In addition, gases like $\mathrm{O}_{2}, \mathrm{CO}_{2}$, $\mathrm{SO}_{2}$ or $\mathrm{NO}_{2}$ play a bigger role in the corrosion mechanism during atmospheric exposure. ${ }^{1}$ In particular, atmospheric concentrations of $\mathrm{CO}_{2}$ can influence the surface $\mathrm{pH}$ and change the composition of the corrosion products. ${ }^{2}$

As a result, there is a lack of agreement between the corrosion rates found in atmospheric field exposure compared to immersion tests or other accelerated tests. ${ }^{4}$ Therefore, the corrosion behavior in atmospheric environments cannot be predicted from results obtained under immersion conditions. To capture the behavior of $\mathrm{Mg}$ in the real service environment the assessment of the corrosion performance should be carried out under atmospheric exposure. Unfortunately, the available methods to determine corrosion rates under atmospheric corrosion conditions are limited.

Mass loss measurements on $\mathrm{Mg}$ are carried out by removing the corrosion products after the exposure period, for example with a chromic acid solution. ${ }^{5}$ The amount of metal loss is determined by weighing the sample before exposure and after the removal of the corrosion products. This method only provides an average corrosion

\footnotetext{
*Electrochemical Society Student Member.

**Electrochemical Society Fellow.

${ }^{\mathrm{z}}$ E-mail: virtanen@ww.uni-erlangen.de
}

rate over the exposure time and no information about the kinetics during exposure. If the corrosion rate changes during exposure, multiple samples are needed to capture the kinetics. Moreover, the process of corrosion product removal is destructive and therefore the effect of different exposure conditions, e.g. changes in relative humidity, temperature, or wet and dry cycles, cannot be studied on the same sample.

In controlled laboratory experiments without runoff, mass gain measurements can be used to follow the corrosion progress. However, since different corrosion products form with different exposure conditions or different alloys, a direct comparison of different systems based on mass gain is difficult. In addition, to obtain the dry mass gain value, the exposure needs to be interrupted by the drying process. This characteristic is not suitable for a monitoring technique. To overcome this limitation some studies perform wet mass gain measurements that include the weight of the absorbed water. ${ }^{2}$

Electrical resistance sensors based on the reduction of the cross section of a metal track by corrosion can be employed to monitor atmospheric corrosion in real time. ${ }^{6}$ The method has been employed to study carbon steel and zinc exposed in accelerated tests, ${ }^{6,7}$ but not yet for Mg alloys. Possible errors of the resistance method could be caused by a conductive electrolyte film that influences the measured resistance. $^{7}$

The primary cathodic reaction of $\mathrm{Mg}$ alloy corrosion in aqueous electrolytes is generally believed to be hydrogen evolution. ${ }^{1,2}$ Therefore, $\mathrm{H}_{2}$ evolution measurements are frequently used to determine corrosion rates of $\mathrm{Mg}$ samples under immersion conditions. This relies on the assumption that under open circuit conditions the anodic dissolution of one $\mathrm{Mg}$ atom (Equation 1) is accompanied by the cathodic evolution of one $\mathrm{H}_{2}$ gas molecule (Equation 2). Although it is often claimed that $\mathrm{Mg}$ corrosion is highly insensitive to the concentration of $\mathrm{O}_{2},{ }^{8,9}$ it is possible that the $\mathrm{O}_{2}$ reduction reaction (ORR) can contribute to the cathodic processes (Equation 3). In a recent paper Silva et al. ${ }^{10}$ provided evidence for the relevance of ORR in $\mathrm{Mg}$ corrosion.

$$
\begin{gathered}
\mathrm{Mg} \rightarrow \mathrm{Mg}^{2+}+2 e^{-} \\
2 \mathrm{H}_{2} \mathrm{O}+2 e^{-} \rightarrow \mathrm{H}_{2}+2 \mathrm{OH}^{-} \\
\mathrm{O}_{2}+2 \mathrm{H}_{2} \mathrm{O}+4 e^{-} \rightarrow 4 \mathrm{OH}^{-}
\end{gathered}
$$

A volumetric approach is widely used to collect and measure the amount of evolved $\mathrm{H}_{2}$ gas (Figure 1a). The evolved $\mathrm{H}_{2}$ is collected 

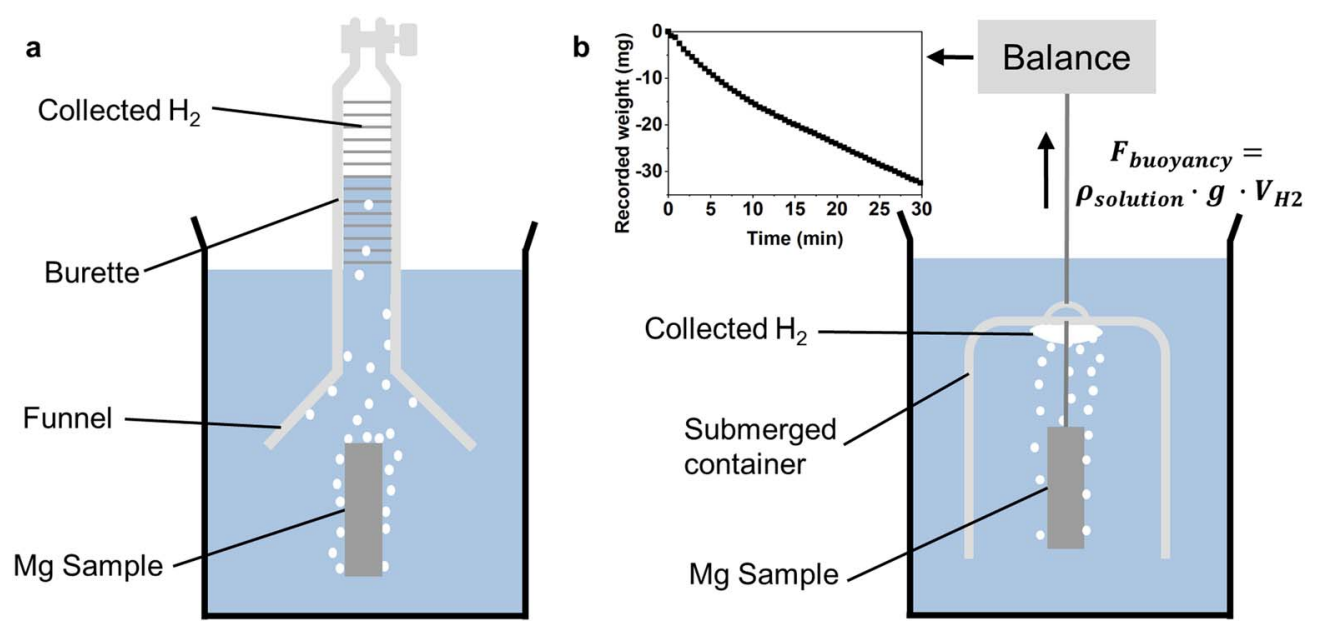

Figure 1. Schematic representation of the (a) volumetric and (b) gravimetric experimental setup for $\mathrm{H}_{2}$ gas collection under immersion conditions.

with a funnel, inserted in an inverted burette that is initially filled with electrolyte. The amount of $\mathrm{H}_{2}$ is determined volumetrically by reading the level of electrolyte displaced by $\mathrm{H}_{2}$ gas. This setup has only limited sensitivity and accuracy, hence being not very suitable for low amounts of evolved $\mathrm{H}_{2} \cdot{ }^{11}$ A new gravimetric method, originally presented by Curioni, ${ }^{12}$ has been shown to exhibit a very high sensitivity for the detection of evolved $\mathrm{H}_{2} \cdot{ }^{13}$ This method relies on the buoyancy change exerted by the evolved $\mathrm{H}_{2}$ gas that can be measured by recording the weight change of a submerged $\mathrm{H}_{2}$ collection container with a balance (Figure 1b). The weight readings can be automatically recorded by a computer to monitor the $\mathrm{H}_{2}$ evolution rate with high time resolution. This way the instantaneous corrosion rate of $\mathrm{Mg}$ samples can be monitored in real-time without any perturbation of the system. ${ }^{13}$

The aim of this work is to present a non-destructive monitoring technique, based on the gravimetric $\mathrm{H}_{2}$ evolution method, to measure real-time atmospheric $\mathrm{Mg}$ alloy corrosion rates during exposure to a humid environment. A correction to compensate for temperature and atmospheric pressure variations during the experiment was developed and evaluated. The new technique was applied to monitor the atmospheric corrosion rate of commercial Mg alloys AZ31 and AZ91 with different amounts of salt $(\mathrm{NaCl})$ contamination. The obtained results were compared to mass loss data to validate the new technique. The role of ORR in the cathodic processes on Mg alloy atmospheric corrosion was investigated. Possible applications and also experimental limitations of the gravimetric atmospheric $\mathrm{H}_{2}$ evolution method are discussed.

\section{Experimental}

Materials and sample preparation.- $\mathrm{Mg}$ alloy AZ31 sheet material supplied by MgF Magnesium Flachprodukte GmbH, Germany and die cast Mg alloy AZ91 produced by DGS Druckgusssysteme AG, Germany were used in this study. The chemical composition of the high purity materials is listed in Table I. Specimens with approximate dimensions of $30 \times 20 \times 2-3 \mathrm{~mm}^{3}$ were prepared from the as received material and a hole was drilled to attach a nylon string. The sample surface was prepared by grinding to 1200 grit with $\mathrm{SiC}$ paper and cleaning with ethanol. Prior to exposure the samples were contaminated with three different amounts of $\mathrm{NaCl}\left(14 \mu \mathrm{g} / \mathrm{cm}^{2}, 70 \mu \mathrm{g} / \mathrm{cm}^{2}\right.$ and $\left.200 \mu \mathrm{g} / \mathrm{cm}^{2}\right)$. $\mathrm{NaCl}$ was deposited by repeated, homogeneous

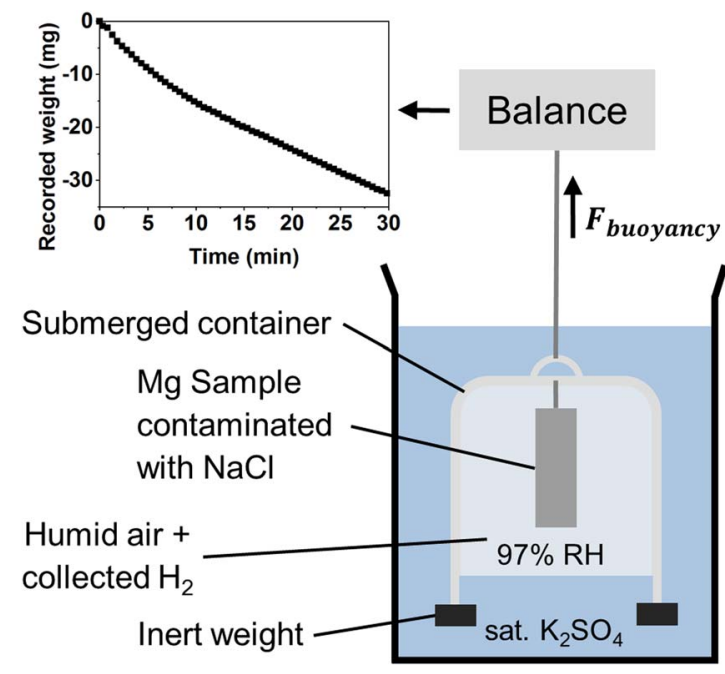

Figure 2. Schematic representation of the gravimetric experimental setup for atmospheric $\mathrm{H}_{2}$ evolution measurements.

spraying of a solution of 80 vol- $\%$ Ethanol $/ 20$ vol- $\%$ water saturated with $\mathrm{NaCl}$ as described previously. ${ }^{2}$

Gravimetric setup for atmospheric $\mathrm{H}_{2}$ evolution monitoring.The setup to measure $\mathrm{H}_{2}$ evolution rates under atmospheric exposure is schematically shown in Figure 2. The $\mathrm{Mg}$ sample is submerged inside a glass container that collects the evolved $\mathrm{H}_{2}$. The air in the container is only partly removed with a syringe and plastic tube to have the sample surrounded by humid air. An inert weight at the bottom of the container ensures stable submersion of the container. The setup used in this study is designed as an open system with the air volume around the sample being in direct contact with the solution. The relative humidity $(\mathrm{RH})$ of this air volume can be controlled with saturated salt solutions. The equilibrium RH over different saturated salt solutions is slightly temperature-dependent. ${ }^{14}$ In addition to saturated salt solutions, glycerol-water mixtures can be used to tune the

Table I. Composition (wt\%) of the tested materials.

\begin{tabular}{cccccccccc} 
& $\mathrm{Al}$ & $\mathrm{Zn}$ & $\mathrm{Mn}$ & $\mathrm{Si}$ & $\mathrm{Zr}$ & $\mathrm{Fe}$ & $\mathrm{Cu}$ & $\mathrm{Ni}$ \\
\hline AZ31 & 3.24 & 1.03 & 0.359 & 0.0218 & 0.00109 & 0.00271 & 0.0017 & $<0.001$ & $\mathrm{Mg}$ \\
AZ91 & 8.90 & 0.62 & 0.231 & 0.031 & 0.003 & 0.002 & 0.006 & 0.002 & Bal.
\end{tabular}


RH to any desired value. ${ }^{15}$ In this study, experiments were carried out by immersing the glass container in a saturated $\mathrm{K}_{2} \mathrm{SO}_{4}$ solution at room temperature, which results in $\mathrm{RH}$ values of approximately 97\%. The whole assembly together with the sample is attached to a Mettler Toledo AG135 balance with a readability of $0.1 \mathrm{mg}$. Weight data points were recorded automatically every $30 \mathrm{~s}$ and the exposure time was $70 \mathrm{~h}$. Additional experiments without the influence of $\mathrm{O}_{2}$ were carried out in a $0.5 \mathrm{M} \mathrm{Na}_{2} \mathrm{SO}_{3}$ solution. The $\mathrm{O}_{2}$ initially present in the submerged container was removed by purging with $\mathrm{N}_{2}$ gas.

To be able to correct for temperature and pressure influences on the measurement, a PCE THB-40 data logger was employed to log the ambient temperature and pressure during the experiment. Imaging of the surface during exposure was carried out with a USB microscope PCE-MM 400 in order to construct a time-lapse video of the corrosion progress.

Evaluation of the atmospheric hydrogen evolution.-The principle of the new atmospheric monitoring technique is to determine the volume of $\mathrm{H}_{2}$ gas evolved by the $\mathrm{Mg}$ sample. The evolved $\mathrm{H}_{2}$ adds to the volume of air and increases the gas volume beneath the submerged container. According to Archimedes' principle, the evolved $\mathrm{H}_{2}$ decreases the apparent weight of the collection setup due to a buoyant force that is equal to the weight of the displaced fluid volume:

$$
F_{\text {buoyancy }}=\rho_{\text {solution }} \cdot g \cdot V_{\text {displaced }}
$$

where $\rho_{\text {solution }}$ is the density of the solution and $g$ is gravitational acceleration.

At constant temperature and pressure, the volume of the entrapped air and the volume of the collection setup is constant, so that any change in buoyancy is associated with the evolved $\mathrm{H}_{2}$. Thus, the volume of collected $\mathrm{H}_{2}$ in the container can be calculated from the weight change measured by the balance (Equation 5). Note that the net weight reading of the balance $W_{\text {balance }}(t)$ is typically negative because the buoyant force associated with the evolved $\mathrm{H}_{2}$ gas decreases the weight. A minus sign is introduced to yield a positive $\mathrm{H}_{2}$ volume.

$$
V_{H 2}(t)=-\frac{W_{\text {balance }}(t)}{g \rho_{\text {solution }}(t)}
$$

In this case air and $\mathrm{H}_{2}$ gas are treated as ideal gases and the volume of the ideal mixture of air and $\mathrm{H}_{2}$ is assumed to be the sum of the volume of each component. This is justified since the total pressure is on the order of $1 \mathrm{~atm}$. Note that the weight increase of the sample itself due to the growth of corrosion products is insignificant in comparison with the buoyant force of the $\mathrm{H}_{2}$ gas. As pointed out by Curioni, ${ }^{12}$ the weight change of the sample itself is three orders of magnitude smaller compared to the buoyancy effect of the evolved $\mathrm{H}_{2}$.

It is important to realize that if the temperature and pressure are not constant during the experiment, the volume changes of the gas due to these variations are also included in the measured $V_{H_{2}}(t)$ curve. If these effects are not corrected for, they can make a reliable measurement impossible. In the following, a procedure to correct for the effects of temperature and pressure fluctuations is described.

The total volume of gas beneath the collection container as a function of time can be expressed by:

$$
V_{\text {gas }}^{\text {total }}(t)=V_{\text {air }}^{\text {initial }}+V_{H 2}(t)
$$

As described above, this treatment assumes that any changes in the volume of both air and $\mathrm{H}_{2}$ gas are included in the $V_{H_{2}}(t)$ curve as determined from the net weight changes recorded by the balance (Equation 5). The volume of air in the beginning of the experiment $V_{\text {air }}^{\text {inial }}$ can be assessed from buoyancy considerations as follows:

First the volume of the collection assembly $V_{\text {assembly }}$ can be determined from the difference of the weight of the dry setup measured in air $W_{\text {assembly }}^{\text {dry }}$ and the weight of the setup submerged without air $W_{\text {assembly }}^{\text {sub }}$ in a solution with a known density $\rho_{\text {solution }}$ (Equations 7-9).
The apparent weight of an object floating in a fluid is given by the downward gravitational force and the upward buoyant force:

$$
W_{\text {assembly }}^{\text {dry }}=F_{g}-F_{\text {buoyancy }}^{\text {air }}=m_{\text {assembly }} \cdot g-\rho_{\text {air }} \cdot g \cdot V_{\text {assembly }}
$$

$W_{\text {assembly }}^{\text {sub }}=F_{g}-F_{\text {buoyancy }}^{\text {sub }}=m_{\text {assembly }} \cdot g-\rho_{\text {solution }} \cdot g \cdot V_{\text {assembly }}$

Subtracting 8 from 7 and rearranging results in:

$$
V_{\text {assembly }}=\left(W_{\text {assembly }}^{\text {dry }}-W_{\text {assembly }}^{\text {sub }}\right) /\left(g\left(\rho_{\text {solution }}-\rho_{\text {air }}\right)\right)
$$

Note that the density of air $\rho_{\text {air }}$ is small compared to the density of the solution and could be neglected.

In a second step $V_{\text {air }}^{\text {initial }}$ can be obtained by a similar consideration. Comparing the dry total weight of the assembly including the weight of the sample $W_{\text {total }}^{d r y}$, with the initial total weight after submersion with air in the solution $W_{\text {initial }}^{\text {sub }}$, leads to the volume of total displaced fluid:

$$
V_{\text {total }}^{\text {displaced }}=\left(W_{\text {total }}^{\text {dry }}-W_{\text {initial }}^{\text {sub }}\right) /\left(g\left(\rho_{\text {solution }}-\rho_{\text {air }}\right)\right)
$$

$V_{\text {total }}^{\text {displaced }}$ comprises the volume of the collection assembly $V_{\text {assembly }}$, the volume of the sample $V_{\text {sample }}$, and the volume of air $V_{a i r}^{\text {initial }}$, and thus:

$$
V_{\text {air }}^{\text {initial }}=V_{\text {total }}^{\text {displaced }}-V_{\text {assembly }}-V_{\text {sample }}
$$

Although the volume of gas can change due to temperature and pressure fluctuations, the number of gas molecules should only increase if $\mathrm{H}_{2}$ is evolved from the sample. The ideal gas law can be used to calculate the amount of substance associated with the air $/ \mathrm{H}_{2}$ mixture $n_{\text {air } / H_{2}}(t)$ in the total gas volume beneath the collection container $V_{\text {gas }}^{\text {total }}(t)$, where $\mathrm{R}$ is the ideal gas constant:

$$
n_{\text {air } / H 2}(t)=\frac{p_{\text {air } / H 2}(t) \cdot V_{\text {gas }}^{\text {total }}(t)}{R \cdot T(t)}
$$

To correct for changes in temperature and pressure during the experiment, the actual values of the temperature of the experiment $T(t)$ and the partial pressure of the air/ $\mathrm{H}_{2}$ mixture $p_{a i r / H 2}(\mathrm{t})$ are used in this calculation. As previously discussed by Fajardo and Frankel, ${ }^{13}$ the contribution of water vapor has to be considered to determine the partial pressure of the air/ $\mathrm{H}_{2}$ mixture. In a gas volume with a gas/liquid interface, water evaporation takes place until the equilibrium partial pressure of water vapor $p_{H 2 O}$ is reached. The total pressure $p_{T}(\mathrm{t})$ of the resulting gas mixture is given by the partial pressures of the individual gases and can be described by:

$$
p_{T}(t)=p_{\text {air } / H 2}(t)+p_{H 2 O}(t)
$$

On the other hand, the total pressure of the gas underneath the collection container is equal to the atmospheric pressure $p_{a t m}(t)$ plus the hydrostatic pressure due to the column of solution above the container:

$$
p_{T}(t)=p_{\text {atm }}(t)+p_{\text {hydr }}
$$

Thus, the partial pressure of the air/ $\mathrm{H}_{2}$ mixture $p_{a i r / H 2}(\mathrm{t})$ in the submerged gas volume is given by:

$$
p_{\text {air } / H 2}(t)=p_{T}(t)-p_{H 2 O}(t)=p_{a t m}(t)+p_{\text {hydr }}-R H \cdot p_{H 2 O}^{\text {sat }}(t)
$$

Here $p_{a t m}(t)$ was logged during the experiment by the data logger. The hydrostatic pressure $p_{\text {hydr }}$ due to the column of solution above the container was neglected because of the small immersion depths and low density solutions used in this study. The equilibrium partial pressure of water vapor $p_{\mathrm{H} 2 \mathrm{O}}(t)$ is given by the relative humidity $\mathrm{RH}$ and the saturation vapor pressure of water $p_{\mathrm{H} 2 \mathrm{O}}^{\mathrm{sat}}(t)$ which was calculated with an updated form of the Buck equation: ${ }^{16}$

$$
p_{H 2 O}^{\text {sat }}(t)=0.61121 \exp \left[\left(18.678-\frac{T(t)}{234.5}\right)\left(\frac{T(t)}{257.14+T(t)}\right)\right]
$$


After taking all these aspects into account, the amount of substance associated with the evolved $\mathrm{H}_{2}$ can be obtained from the result of Equation 12 by subtracting the intital value $n_{\text {air } / H_{2}}(0)$ :

$$
n_{H 2}(t)=n_{\text {air } / H 2}(t)-n_{\text {air }}=n_{\text {air } / H 2}(t)-n_{\text {air } / H 2}(0)
$$

This is based on the idea that after having corrected for temperature and pressure variations, the amount of substance of air is constant. In the next step, $n_{H 2}(t)$ can be transformed to the $\mathrm{H}_{2}$ charge density $Q_{H 2}(t)$ via Faraday's law:

$$
Q_{H 2}(t)=\frac{n_{H 2}(t) z F}{A}
$$

where $\mathrm{n}$ is the amount of substance, $\mathrm{z}$ is the number of transferred electrons, F is Faraday's constant, A is the electrode area. In this case $\mathrm{z}=2$ electrons are consumed to produce one $\mathrm{H}_{2}$ molecule.

Finally, the $\mathrm{H}_{2}$ current density $i_{H 2}$ can be obtained from the slope of the $Q_{H_{2}}(t)$ curve:

$$
i_{H 2}=\frac{\partial Q_{H 2}(t)}{\partial t}
$$

For the calculation of the $\mathrm{H}_{2}$ current density the data points of $20 \mathrm{~min}$ time intervals were averaged to get a smoother signal.

The density of the solution is another important influence on the measurement as it directly influences the buoyant force (Equation 4). For the purpose of this study the temperature dependency of the density of pure water was calculated with an equation by Bettin and Spieweck: ${ }^{17,18}$

$$
\rho_{0}(T)=\frac{\left(a_{0}+a_{1} T+a_{2} T^{2}+a_{3} T^{3}+a_{4} T^{4}+a_{5} T^{5}\right)}{(1+b T)}
$$

$\left(\mathrm{a}_{0}=9.9983952 \times 10^{2} \mathrm{~kg} / \mathrm{m}^{3} ; \mathrm{a}_{1}=1.6952577 \times 10^{1 \circ} \mathrm{C}^{-1} \mathrm{~kg} / \mathrm{m}^{3} ;\right.$ $\mathrm{a}_{2}=-7.9905127 \times 10^{-3}{ }^{\circ} \mathrm{C}^{-2} \mathrm{~kg} / \mathrm{m}^{3} ; \mathrm{a}_{3}=-4.6241757 \times 10^{-5 \circ} \mathrm{C}^{-3}$ $\mathrm{kg} / \mathrm{m}^{3} ; \mathrm{a}_{4}=1.0584601 \times 10^{-7}{ }^{\circ} \mathrm{C}^{-4} \mathrm{~kg} / \mathrm{m}^{3} ; \mathrm{a}_{5}=-2.8103006 \times$ $\left.10^{-10}{ }^{\circ} \mathrm{C}^{-5} \mathrm{~kg} / \mathrm{m}^{3} ; \mathrm{b}=1.6887236 \times 10^{-2 \circ} \mathrm{C}^{-1}\right)$.

The contribution of dissolved salts to the density of the solution was approximated with a linear form of the equation of state for sea water: ${ }^{19,20}$

$$
\rho(T, S)=\rho_{0}(T)\left[1+\beta_{s} S\right]
$$

where $\mathrm{S}$ is the concentration of total dissolved solids (salinity) expressed in $\mathrm{g} / \mathrm{kg}$ and $\beta_{s}$ is the saline contraction coefficient.

$$
\beta_{s}=\frac{1}{\rho}\left(\frac{\partial \rho}{\partial S}\right)_{T, p}
$$

A $\beta_{s}$ value of $0.78 \times 10^{-3}(\mathrm{~g} / \mathrm{kg})^{-1}$ as suggested for sea water by Vallis ${ }^{21}$ was used as an approximation for the solutions used in this study. Solution density measurements with a hydrometer at room temperature were found to be in good agreement with the values calculated by Equations 20 and 21 .

Gravimetric mass loss measurements.-After collection of $\mathrm{H}_{2}$ during the $70 \mathrm{~h}$ exposure the samples were dried in a desiccator and the dry mass gain $m_{\text {gain }}$ was measured with a Mettler Toledo balance (model XA205DU). The corresponding mass loss of the samples $m_{\text {loss }}$ was determined after cleaning the samples in high purity water $(18.2 \mathrm{M} \Omega \mathrm{cm}$ ) followed by pickling in an aqueous solution of $200 \mathrm{~g} / \mathrm{l}$ $\mathrm{CrO}_{3}$. To compare the results with the $\mathrm{H}_{2}$ measurements the weight loss value was transformed to a charge density via Faraday's Law:

$$
Q_{M L}=\frac{n z F}{A}=\frac{m_{\text {loss }}}{M A} z F=\frac{m_{\text {loss }}}{E W A} F
$$

The alloy composition was considered by calculating the equivalent weight EW (g/equivalent) as a weighted average of $\mathrm{M}_{\mathrm{i}} / \mathrm{z}_{\mathrm{i}}$ for the major alloying elements with the molar mass $M_{i}$ and the mass fraction $\mathrm{f}_{\mathrm{i}}$ assuming congruent dissolution to $\mathrm{Mg}^{2+}, \mathrm{Al}^{3+}, \mathrm{Zn}^{2+}$ and $\mathrm{Mn}^{2+}$ by: 22,23

$$
E W=\left(\sum \frac{f_{i} z_{i}}{M_{i}}\right)^{-1}
$$

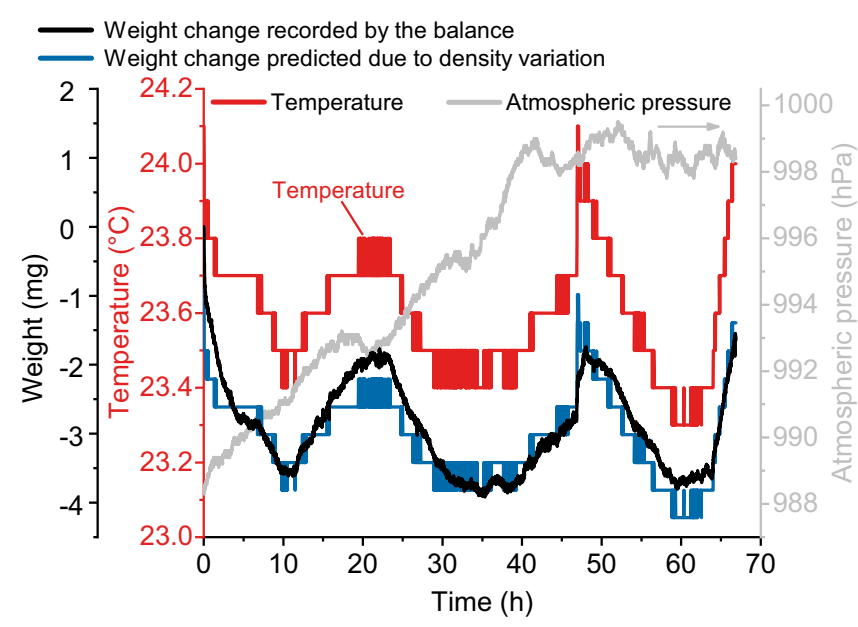

Figure 3. Influence of temperature variations on the weight change of a glass container immersed in $0.1 \mathrm{M} \mathrm{NaCl}$ without air and without $\mathrm{Mg}$ sample.

The EW for AZ31 and AZ91 used in this study were determined to be $12.16 \mathrm{~g} / \mathrm{eq}$ and $11.89 \mathrm{~g} / \mathrm{eq}$ respectively.

The corrosion product ratio, i.e. the total mass of corrosion product $\mathrm{m}_{\mathrm{cp}}$ divided by the mass of the metal ions was calculated from the mass gain and mass loss values to give an indication of the composition of the corrosion products:

$$
X=\frac{m_{c p}}{m_{\text {loss }}}=\frac{m_{\text {gain }}+m_{\text {loss }}}{m_{\text {loss }}}
$$

\section{Results and Discussion}

Baseline and correction.-Experiments without an Mg sample were carried out to point out the effect of temperature and pressure changes during the experiment, and to evaluate if these variations can be compensated for after the measurement. In a first experiment, only a glass container without $\mathrm{Mg}$ sample was immersed in $0.1 \mathrm{M} \mathrm{NaCl}$ with all the air removed. Figure 3 shows the weight signal recorded by the balance together with the temperature and atmospheric pressure values from the data logger during the experiment.

The weight signal shows variations that clearly follow the course of the temperature. As there is no gas present that could react to pressure fluctuations, the weight signal is independent of the atmospheric pressure. The variations of the weight signal can be explained by the temperature dependence of the density of the solution that causes a change in the buoyancy of the glass container volume. A decrease in temperature leads to an increase in the density of the solution that according to Equation 4 results in an increasing buoyant force that lowers the apparent weight of the container. The weight changes due to this effect can be predicted by using the temperature dependent solution density (Equations 20 and 21) and the volume displaced by the glass container (Vcontainer $\left.=16.5 \mathrm{~cm}^{3}\right)$ that is assumed to be constant. As can be seen in Figure 3, the predicted weight change matches well with the recorded weight change. The fact that temperature variations of $0.1^{\circ} \mathrm{C}$ can be readily detected by the balance indicates the high sensitivity of the gravimetric method. Although the effect of temperature fluctuations on the density of the solution is small and probably not significant for experiments at room temperature, it can be subtracted from the measured data.

The baseline of the experiment without $\mathrm{Mg}$ sample but with approximately $37 \mathrm{ml}$ of air in the submerged container is shown in Figure 4 . The air volume inside the container expands and compresses due to changes in the temperature and atmospheric pressure. Consequently, also the buoyant force and the weight signal are directly influenced by these local climatic changes during the experiment. Interestingly, all peaks and features of the pressure signal can be found in the weight signal recorded by the balance. 


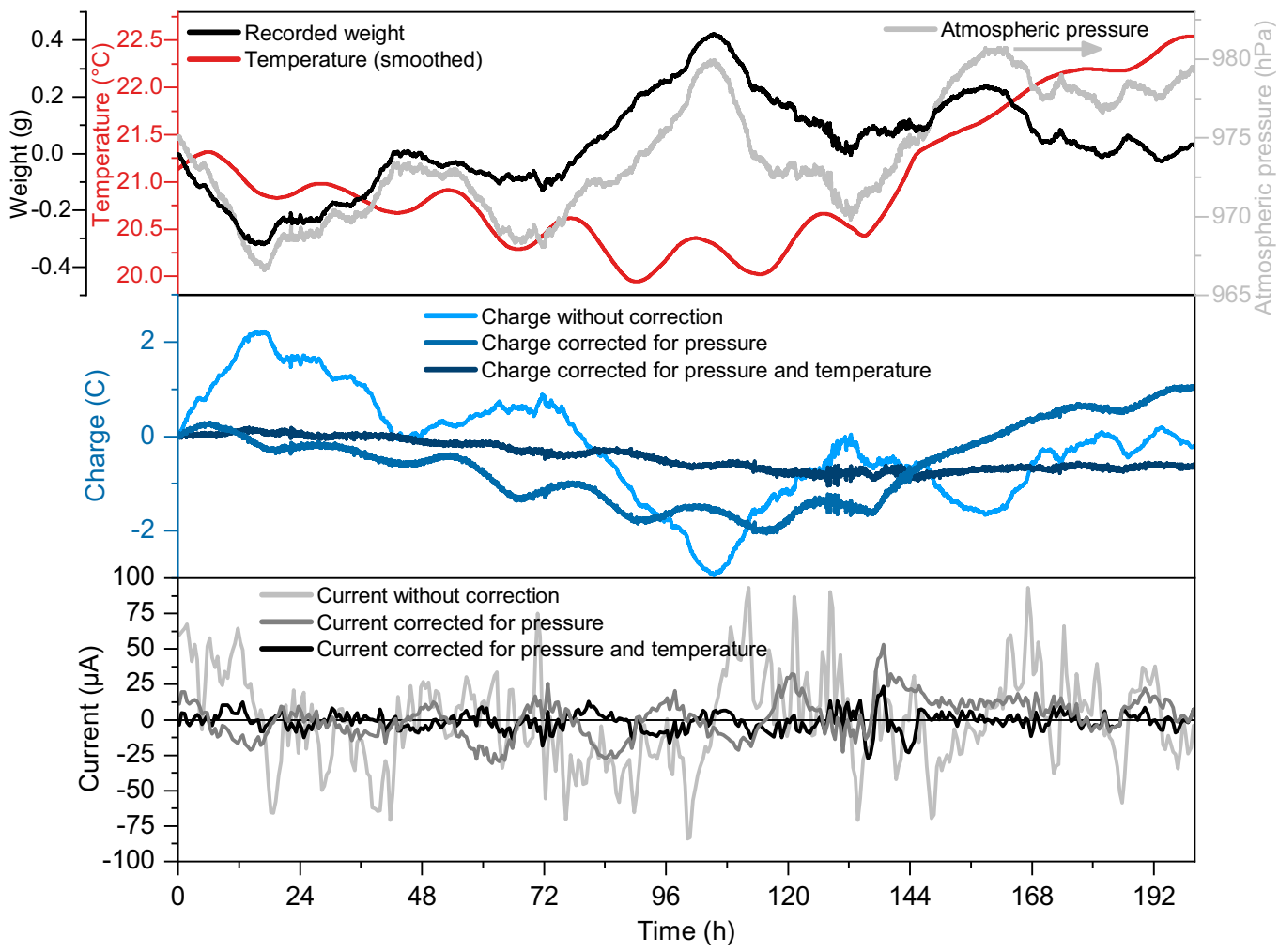

Figure 4. Influence of temperature and atmospheric pressure variations on the baseline of the gravimetric experiment without $\mathrm{Mg}$ sample but with $37 \mathrm{ml}$ air inside the container submerged in sat. $\mathrm{K}_{2} \mathrm{SO}_{4}$ solution. A stable charge and current baseline was obtained after correcting for both temperature and pressure variations.

Since changes in the atmospheric pressure during the experiment cannot be avoided or predicted, it was attempted to correct for these changes, as described in the experimental section. In this baseline experiment, there is no $\mathrm{Mg}$ sample and consequently no $\mathrm{H}_{2}$ evolution. Nevertheless, the weight data was transformed to an $\mathrm{H}_{2}$ equivalent charge to demonstrate the effects of pressure and temperature on the measurement. The uncorrected $\mathrm{H}_{2}$ equivalent charge corresponding to the measured weight changes, together with the equivalent charge corrected for pressure, and the equivalent charge corrected for both pressure and temperature are also shown in Figure 4. The curve without correction was obtained using the temperature and atmospheric pressure values at the start of the experiment. In this case, changes in the weight signal directly translate to changes in the calculated charge and the associated current. In an experiment with $\mathrm{Mg}$ sample these changes are superimposed on the $\mathrm{H}_{2}$ signal and therefore would have a strong effect on the measurement. The equivalent charge curve corrected for the pressure was calculated with the actual pressure values from the data logger, but ignoring the temperature variations. It can be seen that the equivalent charge curve corrected for only the pressure follows exactly the course of the temperature signal. The correction of both pressure and temperature variations results in a stable baseline for the equivalent charge curve and the associated current. Consequently, if the changes in climatic conditions are taken into account, the influences of temperature and pressure variations can be compensated for. It is worth noting that this correction can be deployed also to immersion experiments carried out with the gravimetric method. The effect is proportional to the amount of gas inside the collection setup. Therefore, it becomes more relevant for longer immersion times and higher amounts of collected $\mathrm{H}_{2}$.

The effect of the correction on a measurement of an AZ91 Mg alloy sample contaminated with $70 \mu \mathrm{g} / \mathrm{cm}^{2} \mathrm{NaCl}$ is illustrated in Figure 5 . The slow decay of the atmospheric pressure during the first part of the experiment tends to increases the volume of the gas inside the container. On the contrary, the drop in temperature tends to decrease the volume of the gas. In the beginning, these effects seem to cancel each other and the uncorrected charge curve matches the corrected charge curve. A deviation between the curves becomes evident in the parts of the measurement where the temperature rises. After 45 hours, a sudden increase in the atmospheric pressure leads to a decrease in the slope of the uncorrected charge curve. This effect disappears in the corrected charge curve which shows a steady increase with time. As a result of the efficient correction, reliable charge curves can be

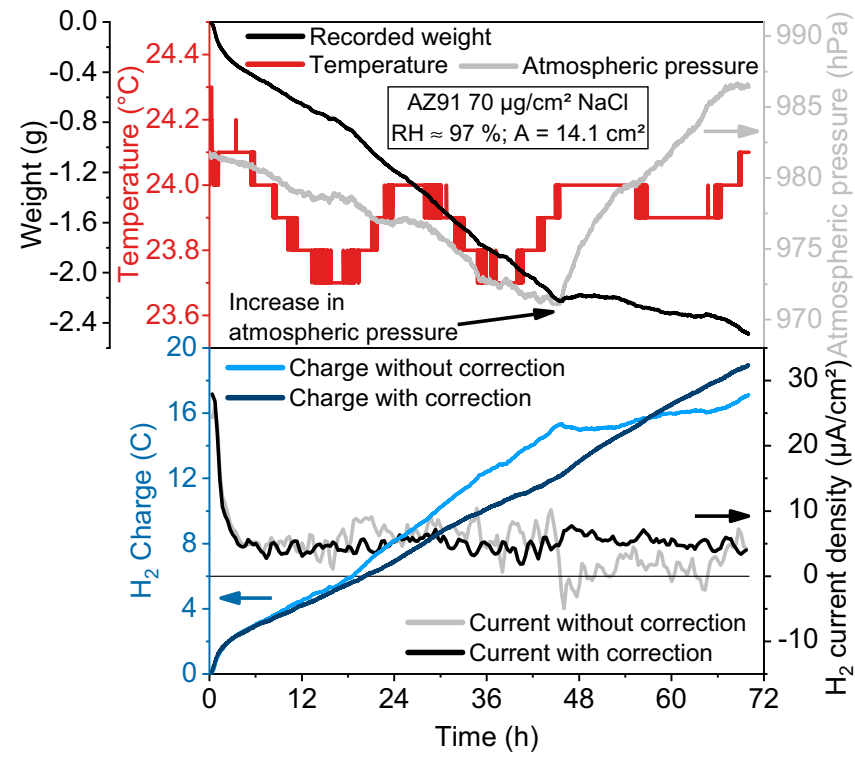

Figure 5. Effective correction of temperature and pressure influences on the atmospheric $\mathrm{H}_{2}$ measurement with $\mathrm{Mg}$ alloy sample (AZ91 contaminated with $\left.70 \mu \mathrm{g} / \mathrm{cm}^{2} \mathrm{NaCl}\right)$. 


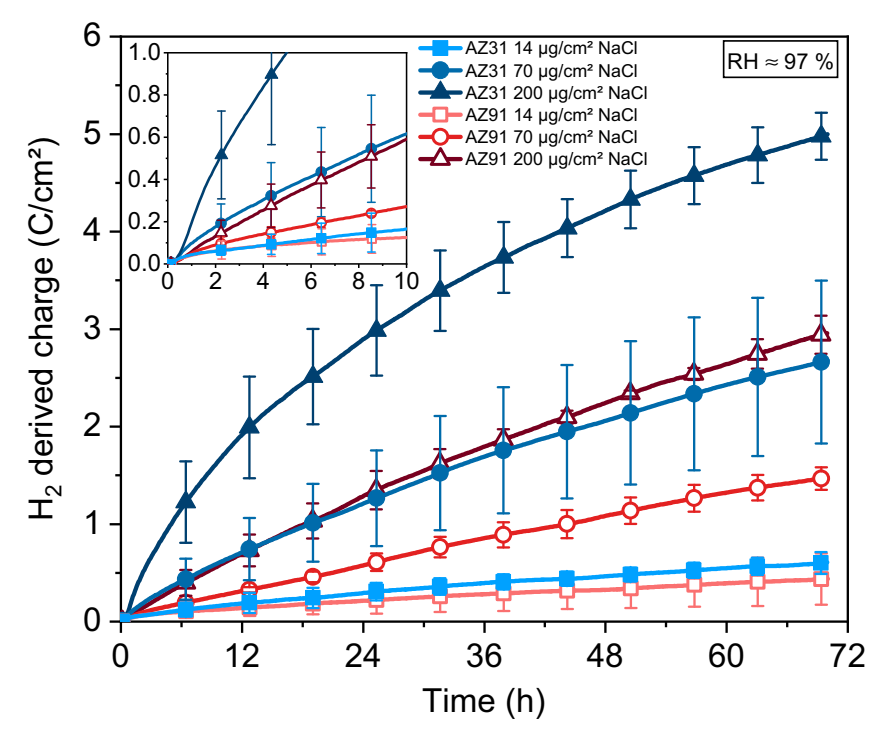

Figure 6. Corrected $\mathrm{H}_{2}$ charge density of AZ31 and AZ91 specimens with different $\mathrm{NaCl}$ contamination exposed in the humid environment for 70 hours.

measured and monitoring of the $\mathrm{H}_{2}$ current density of the sample is possible in real-time during the whole experiment.

Gravimetric monitoring of hydrogen evolution during atmospheric exposure of AZ31 and AZ91.-The new atmospheric $\mathrm{H}_{2}$ monitoring technique was applied to study the effect of different amounts of $\mathrm{NaCl}$ contamination on the $\mathrm{Mg}$ alloys AZ31 and $\mathrm{AZ91}$. The resulting $\mathrm{H}_{2}$ charge density for $70 \mathrm{~h}$ exposure at a $\mathrm{RH}$ of $97 \%$ is shown in Figure 6. The measurements of replicate samples were averaged and plotted together with the standard deviation. Reliable measurements of the atmospheric $\mathrm{H}_{2}$ evolution are possible due to the sensitivity of the gravimetric technique in combination with the correction of temperature and pressure variations described above. Even the low amounts of $\mathrm{H}_{2}$ evolved by the $14 \mu \mathrm{g} / \mathrm{cm}^{2} \mathrm{NaCl}$ samples can be readily detected. Figure 7 shows the $\mathrm{H}_{2}$ current density that can be obtained from the slope of the charge curves. As a result, real-time atmospheric $\mathrm{Mg}$ alloy corrosion rates can be monitored at any point in time during the exposure.

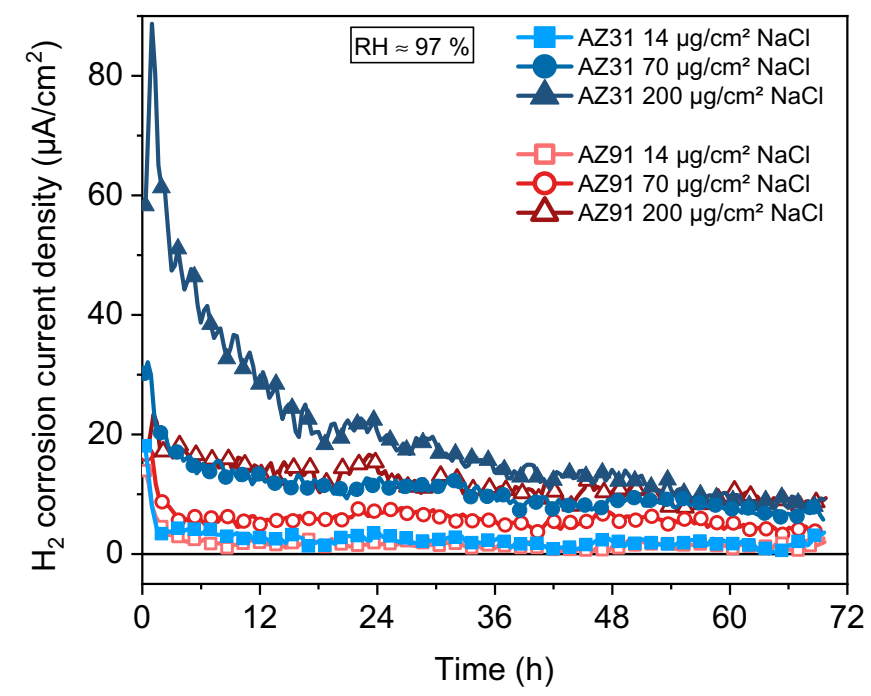

Figure 7. Real-time atmospheric $\mathrm{H}_{2}$ current density of AZ31 and AZ91 specimens with different $\mathrm{NaCl}$ contamination exposed in the humid environment for 70 hours.
From parallel imaging of the surface during exposure (see videos in supplementary material), it is evident that the corrosion attack is highly localized and progresses in the form of filiform tracks. It can also be seen that with an increased amount of deposited salt the amount of absorbed water to form a corrosive electrolyte increases. While for the $14 \mu \mathrm{g} / \mathrm{cm}^{2}$ samples the aqueous electrolyte is very thin, visible droplets appear on the surface of the $70 \mu \mathrm{g} / \mathrm{cm}^{2}$ and 200 $\mu \mathrm{g} / \mathrm{cm}^{2} \mathrm{NaCl}$ samples. As can be expected and as shown before, ${ }^{2,24}$ increasing the amount of $\mathrm{NaCl}$ deposited increases the corrosion rate. The chloride concentration of the electrolyte formed on the sample is independent of the amount of salt deposited but depends on the RH during exposure. However, a higher salt deposition density increases the uptake of water to reach the equilibrium electrolyte concentration for a given RH. Therefore, more electrolyte is available to cover the surface and increase the active area. In addition, this increases the possibility of micro-galvanic coupling between more remote cathodic intermetallic particles and the local anodic sites. ${ }^{3,24}$ In accordance with a model by Curioni et al., ${ }^{25,26}$ the increased remote current provided by the cathodic sites could further promote the depassivation of the anodic sites, leaving bare Mg directly exposed to the electrolyte. This can induce substantial metal loss and local $\mathrm{H}_{2}$ evolution at the local anodic sites of the filiform head. Hence, the possibility of more distant galvanic coupling can lead to an overall increase of the corrosion rate.

AZ91 evolves less $\mathrm{H}_{2}$ compared to AZ31. This finding is in agreement with results of Esmaily et al. ${ }^{27}$ who showed that higher Al content in the alloy decreased the atmospheric corrosion rate. They attributed this effect to an $\mathrm{Al}$ enriched layer at the bottom of the corrosion product film that shows increasing protective properties. It was further suggested that $\mathrm{Al}$ assists in the formation of a protective carbonate-containing corrosion product that shows characteristics of layered double hydroxides (LDHs) ${ }^{28}$ Some researchers argue that the more noble $\beta$-phase $\left(\mathrm{Mg}_{17} \mathrm{Al}_{12}\right)$ found in AZ91 can form a continuous network and act as a barrier for corrosion propagation. ${ }^{29,30}$

The corrosion rate shows a general decrease with time, and differences in the corrosion rate between the different alloys and salt contamination levels diminish toward the end of exposure. The slowing down can be attributed to the blocking of active sites with electronically insulating corrosion products. ${ }^{31}$ The increasing coverage of the sample with a corrosion product film inhibits the propagation of the active filaments. In addition, also the film on the passive regions could become more protective. For AZ91, another explanation could be the barrier effect of the $\beta$-phase, whose fraction on the surface could increase with the preferential dissolution of the Mg matrix.

Comparison with mass loss._-Mass loss measurements performed after the exposure were carried out and the charge density results are compared with the charge density of the total amount of collected $\mathrm{H}_{2}$ in Figure 8 and Table II. In general, a good correlation can be seen and both techniques seem to give accurate measures of the amount of corrosion that has occurred on the different samples. The general trends of the atmospheric $\mathrm{H}_{2}$ results, that the amount of deposited salt increases the corrosivity and that AZ91 is more corrosion resistant then AZ31, are confirmed by the mass loss results.

It should be pointed out that the high standard deviation observed for some systems is not necessarily an indicator for the accuracy of the methods, but is mainly related to different total amount of corrosion between nominally identical samples. The scatter is attributed to differences in the homogeneity of the salt distribution due to the spraying process. The spread was especially large on AZ31 with $70 \mu \mathrm{g} / \mathrm{cm}^{2}$ $\mathrm{NaCl}$. As can be seen in Figure 9, both methods agree on the ranking of the amount of corrosion that has occurred on the replicate samples. Note that the charge ratio $\mathrm{Q}_{\mathrm{H} 2} / \mathrm{Q}_{\mathrm{ML}}$ is not influenced by these differences in the corrosion rate between replicate samples, as it includes the cumulative amount of charge measured for all of the replicate samples. This ratio is therefore suitable to estimate the agreement between the two methods. Although the charge density of the $\mathrm{H}_{2}$ method is always slightly lower compared to the mass loss results, there is a very good agreement $\left(\mathrm{Q}_{\mathrm{H} 2} / \mathrm{Q}_{\mathrm{ML}}\right.$ up to $\left.\approx 90 \%\right)$ in the case of $\mathrm{AZ31}$. This 


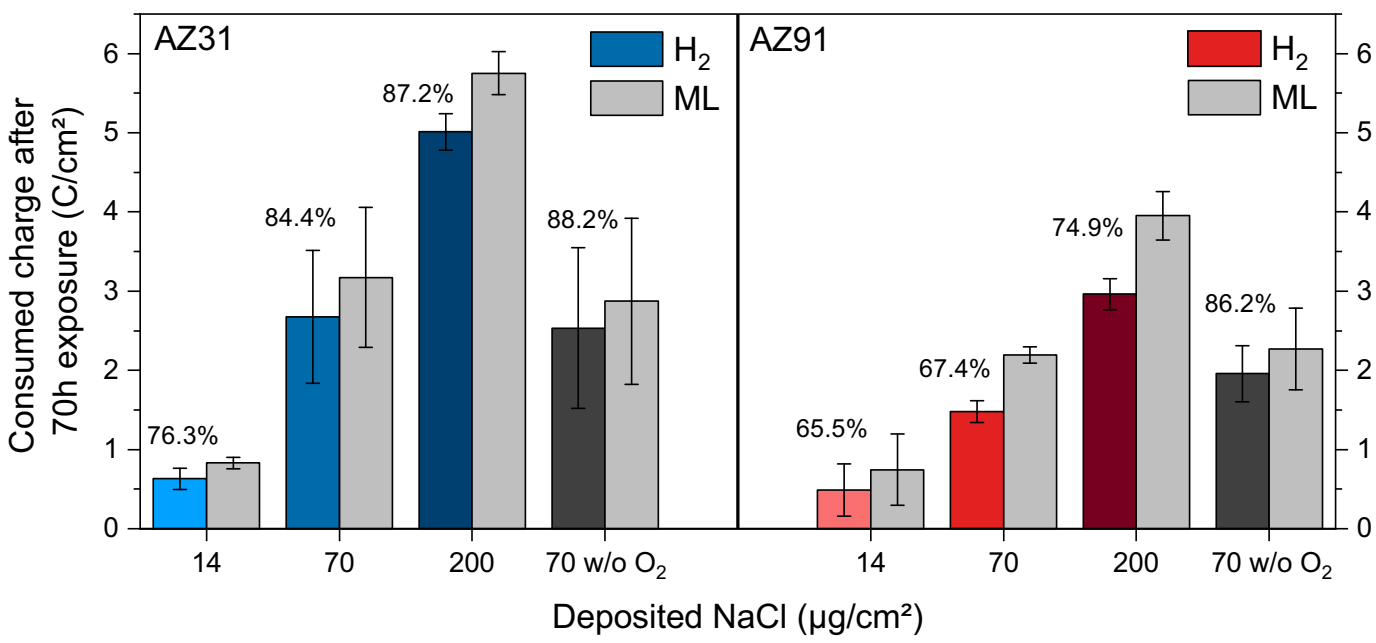

Figure 8. Consumed charge per total electrode area after $70 \mathrm{~h}$ exposure for $\mathrm{AZ} 31$ and $\mathrm{AZ} 91$ with different amount of $\mathrm{NaCl}$ contamination as determined by atmospheric $\mathrm{H}_{2}$ evolution measurements and mass loss measurements. Average values of replicate samples are shown and error bars represent one standard deviation. The ratio $\mathrm{Q}_{\mathrm{H} 2} / \mathrm{Q}_{\mathrm{ML}}$ is given in $\%$.

Table II. Average consumed charge $\mathrm{Q}_{\mathrm{H} 2}, \mathrm{Q}_{\mathrm{ML}}$, Ratio $\mathrm{Q}_{\mathrm{H} 2} / \mathrm{Q}_{\mathrm{ML}}$ and corrosion product ratio after $70 \mathrm{~h}$ exposure.

\begin{tabular}{|c|c|c|c|c|c|}
\hline Alloy & $\begin{array}{l}\mathrm{NaCl} \\
\left(\mu \mathrm{g} / \mathrm{cm}^{2}\right)\end{array}$ & $\begin{array}{l}\mathrm{QH}_{\mathrm{H} 2} \\
\left(\mathrm{C} / \mathrm{cm}^{2}\right)\end{array}$ & $\begin{array}{l}\mathrm{Q}_{\mathrm{ML}} \\
\left(\mathrm{C} / \mathrm{cm}^{2}\right)\end{array}$ & $\begin{array}{l}\mathrm{Q}_{\mathrm{H} 2} / \mathrm{Q}_{\mathrm{ML}} \\
(\%)\end{array}$ & $\begin{array}{l}\text { Corrosion product ratio } \\
\mathrm{m}_{\mathrm{CP}} / \mathrm{m}_{\text {loss }}\end{array}$ \\
\hline AZ31 & 14 & $0.63 \pm 0.13$ & $0.83 \pm 0.07$ & 76.3 & 2.65 \\
\hline AZ31 & 70 & $2.68 \pm 0.84$ & $3.17 \pm 0.89$ & 84.4 & 2.38 \\
\hline AZ31 & 70 w/o O2 & $2.53 \pm 1.01$ & $2.87 \pm 1.05$ & 88.2 & 2.37 \\
\hline AZ31 & 200 & $5.01 \pm 0.23$ & $5.75 \pm 0.27$ & 87.2 & 2.45 \\
\hline AZ91 & 14 & $0.49 \pm 0.33$ & $0.74 \pm 0.45$ & 65.5 & 2.59 \\
\hline AZ91 & 70 & $1.48 \pm 0.14$ & $2.19 \pm 0.10$ & 67.4 & 2.57 \\
\hline AZ91 & 70 w/o O2 & $1.96 \pm 0.35$ & $2.27 \pm 0.51$ & 86.2 & 2.51 \\
\hline AZ91 & 200 & $2.96 \pm 0.20$ & $3.95 \pm 0.30$ & 74.9 & 2.36 \\
\hline
\end{tabular}

means that it is not only possible to measure reliable instantaneous or steady state $\mathrm{H}_{2}$ evolution rates but also the total amount of collected $\mathrm{H}_{2}$ is valid.

Possible explanations for the remaining discrepancy between collected $\mathrm{H}_{2}$ and the mass loss results include the following points:

a) $\mathrm{H}_{2}$ could be the dissolved into the solution. If $\mathrm{H}_{2}$ gas is dissolved in the aqueous phase it does not exert a buoyant force any more. According to Henry's law (Equation 26) there is a driving force for $\mathrm{H}_{2}$ to enter the solution to reach an equilibrium concentration $C_{H 2}^{s o l}$ that is proportional to the $\mathrm{H}_{2}$ partial pressure $p_{H_{2}}$ in the gas

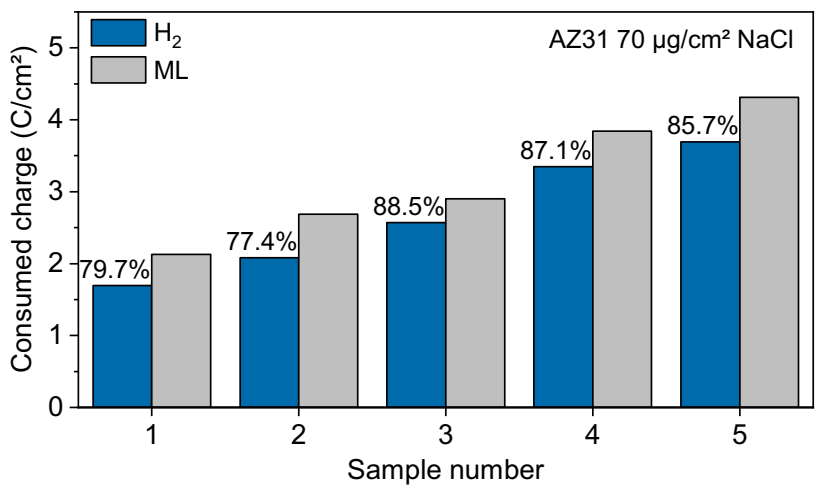

Figure 9. Consumed charge per total electrode area for five replicate samples of AZ31 with $70 \mu \mathrm{g} / \mathrm{cm}^{2} \mathrm{NaCl}$ exposed for $70 \mathrm{~h}$. The ratio $\mathrm{Q}_{\mathrm{H} 2} / \mathrm{Q}_{\mathrm{ML}}$ is given in $\%$. phase:

$$
C_{H 2}^{s o l}=k_{H} p_{H 2}
$$

where $k_{H}$ is the proportionality constant for $\mathrm{H}_{2}\left(\mathrm{k}_{\mathrm{H}}=7,8 \times\right.$ $10^{-6} \mathrm{molm}^{-3} \mathrm{~Pa}^{-1}$ at $\left.25^{\circ} \mathrm{C}\right){ }^{32}$ However, the beaker containing the solution is open to air in the laboratory. Since $\mathrm{H}_{2}$ is also lost at this interface, it is impossible to predict the amount of $\mathrm{H}_{2}$ that dissolves into the solution. To evaluate the issue of $\mathrm{H}_{2}$ dissolution into the solution, an experiment was performed where a known volume of $\mathrm{H}_{2}$ was placed together with a known volume of air using the same setup submerged in deionized water. The weight change was monitored for $72 \mathrm{~h}$ and the results in Figure 10 shows that $\mathrm{H}_{2}$ is continually removed from the air/ $\mathrm{H}_{2}$ mixture. After 72 $\mathrm{h}$ the $\mathrm{H}_{2}$ charge is decreased by approximately $8 \%$. This indicates that the dissolution of $\mathrm{H}_{2}$ into the solution takes place and can explain part of the missing $\mathrm{H}_{2}$.

b) $\mathrm{H}_{2}$ could be lost by dissolution into the $\mathrm{Mg}$ sample. The hydrogen solubility in $\mathrm{Mg}$ at an $\mathrm{H}_{2}$ pressure of 1 bar at room temperature is 0.002 at $\%{ }^{33}$ Since the partial pressure of $\mathrm{H}_{2}$ in the experiment is much smaller than $1 \mathrm{bar}$, the dissolved amount of $\mathrm{H}_{2}$ should be even lower. Furthermore, the dissolution into the sample can be impeded by the corrosion product film and $\mathrm{MgH}_{2}$ formation, which has a very low diffusivity of $\mathrm{H}_{2} \cdot{ }^{33}$

c) The mass loss technique could have overestimated the amount of corrosion that has occurred. Even though an uncorroded specimen showed only negligible weight loss, it is possible that the pickling process has led to excessive cleaning during the removal of the corrosion products of the corroded samples.

d) The contribution of the ORR as a competing cathodic reaction can lead to $\mathrm{Mg}$ oxidation that is not registered by the gravimetric technique, since no $\mathrm{H}_{2}$ gas is generated. On the contrary, if part of the corrosion reaction has occurred via ORR this would consume 


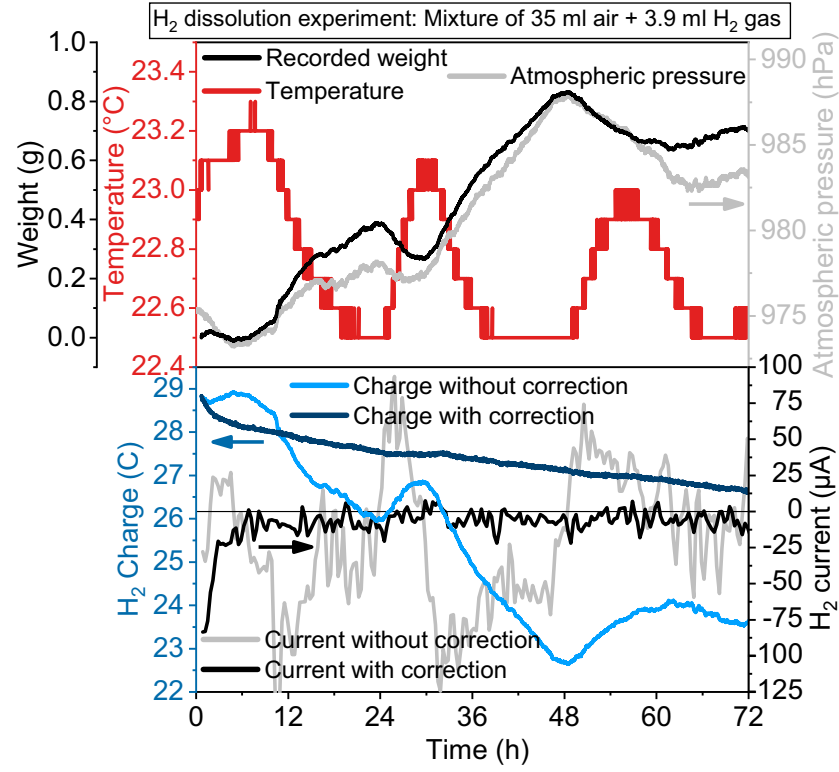

Figure 10. Gravimetric experiment to monitor $\mathrm{H}_{2}$ dissolution into the solution. At the beginning of the experiment $3.9 \mathrm{ml} \mathrm{H}_{2}$ were placed together with $35 \mathrm{ml}$ air in the collection assembly submerged in deionized water. The continuous decrease of the corrected $\mathrm{H}_{2}$ charge curve and the negative $\mathrm{H}_{2}$ current correspond to the removal of $\mathrm{H}_{2}$ from the gas phase due to dissolution into water.

$\mathrm{O}_{2}$ molecules from the gas phase and therefore decrease the buoyant force measured by the balance.

For AZ91 the discrepancy between the $\mathrm{H}_{2}$ method and the mass loss technique is greater which cannot be explained with point a). The effect of $\mathrm{H}_{2}$ dissolution into the solution should be comparable for both alloys if similar amounts of evolved $\mathrm{H}_{2}$ are compared. Although it was reported that hydrogen can diffuse into the $\beta$-phase in AZ91, ${ }^{34}$ it is unlikely that the hydrogen uptake of the $\beta$-phase can account for the extent of the differences observed between AZ31 and AZ91. For these reasons, it can be hypothesized that the ORR plays a role in the atmospheric corrosion of $\mathrm{Mg}$ alloys and that the role of ORR is more pronounced on AZ91 than on AZ31.

To further address this issue, additional experiments without the influence of $\mathrm{O}_{2}$ were conducted in a $0.5 \mathrm{M} \mathrm{Na}_{2} \mathrm{SO}_{3}$ solution with $\mathrm{AZ} 31$ and AZ91 samples contaminated with $70 \mu \mathrm{g} / \mathrm{cm}^{2} \mathrm{NaCl}$. $\mathrm{Na}_{2} \mathrm{SO}_{3}$ acts as an $\mathrm{O}_{2}$ scavenger that reacts with the dissolved $\mathrm{O}_{2}$ without generating other gaseous species (Equation 27). $\mathrm{O}_{2}$ initially present in the air surrounding the sample was eliminated by purging with $\mathrm{N}_{2}$.

$$
2 \mathrm{Na}_{2} \mathrm{SO}_{3}+\mathrm{O}_{2} \rightarrow 2 \mathrm{Na}_{2} \mathrm{SO}_{4}
$$

The results of the experiments without $\mathrm{O}_{2}$ are also displayed in Figure 8 and Table II. It can be seen that the mass loss values are comparable to the corresponding experiment with $\mathrm{O}_{2}$. However, the total amount of detected $\mathrm{H}_{2}$ is much closer to the mass loss values in the case where $\mathrm{O}_{2}$ was eliminated. The ratio $\mathrm{Q}_{\mathrm{H} 2} / \mathrm{Q}_{\mathrm{ML}}$ increases slightly from $84.4 \%$ to $88.2 \%$ for AZ31 whereas for AZ91 it increases significantly from $67.4 \%$ to $86.2 \%$. This is a strong indication that the ORR does play a role in $\mathrm{Mg}$ atmospheric corrosion. The influence seems to be more pronounced on AZ91, which might be connected to the larger amounts of the Al-rich second phase $\left(\mathrm{Mg}_{17} \mathrm{Al}_{12}\right)$ found in AZ91 as compared to AZ31. Silva and co-workers studied the consumption of dissolved $\mathrm{O}_{2}$ during the corrosion of commercially pure $\mathrm{Mg}$ immersed in $0.5 \mathrm{M} \mathrm{NaCl}$ with localized corrosion techniques and sensors for dissolved $\mathrm{O}_{2} .{ }^{10}$ They present strong evidence of $\mathrm{O}_{2}$ depletion associated with ORR over both anodically and cathodically active areas. In the case of Mg alloys this implies that ORR could occur predominantly over more noble, cathodically active intermetallic phases like $\mathrm{Mg}_{17} \mathrm{Al}_{12}$. For that reason, the ORR could be more significant on AZ91 compared to AZ31. Moreover, it can be expected that ORR could play a more significant role in the case of atmospheric corrosion compared to immersion, because mass transfer of $\mathrm{O}_{2}$ is faster in thin electrolyte layers.

The exact quantification of the share of ORR to the cathodic processes from the deviation between mass loss and the gravimetric $\mathrm{H}_{2}$ method is complicated by the fact that $\mathrm{H}_{2}$ dissolution effects cannot be excluded. This is suggested by the observation that the $\mathrm{Q}_{\mathrm{H} 2} / \mathrm{Q}_{\mathrm{ML}}-$ ratio does not exceed $90 \%$, even without the influence of $\mathrm{O}_{2}$. Assuming a similar contribution of dissolution effects with and without $\mathrm{O}_{2}$, the apparent percentage of ORR is approximately $4 \%$ and $19 \%$ for AZ31 $70 \mu \mathrm{g} / \mathrm{cm}^{2}$ and AZ91 $70 \mu \mathrm{g} / \mathrm{cm}^{2}$, respectively. It should be noted that the true amount of ORR is even lower because the elimination of $\mathrm{O}_{2}$ gas molecules decreases the measured buoyant force. This leads to an underestimation of the amount of detected $\mathrm{H}_{2}$. While for the consumption of one $\mathrm{O}_{2}$ molecule two $\mathrm{Mg}$ atoms are oxidized, one $\mathrm{H}_{2}$ molecule is released per $\mathrm{Mg}$ atom in the case of water reduction. As a consequence, the true percentage of ORR should be only two-thirds of the apparent, measured values stated above.

The corrosion product ratio given in Table II gives an indication of the composition of the corrosion products formed on the surface during exposure in the humid environment. For both alloys the values are close to the value of 2.4 which is expected for $\mathrm{Mg}(\mathrm{OH})_{2}$. Slightly higher values for AZ91 might be attributed to the contribution of an Al rich corrosion product. For instance, meixnerite $\left(\mathrm{Mg}_{6} \mathrm{Al}_{2}(\mathrm{OH})_{18}\right.$ $\mathrm{x} 4 \mathrm{H}_{2} \mathrm{O}$ ) has been identified with XRD for AM50 exposed in the absence of $\mathrm{CO}_{2} \cdot{ }^{31,35}$ Magnesium hydroxy carbonates that are usually found for exposures with ambient levels of $\mathrm{CO}_{2}$ have corrosion product ratios of around $4 . .^{31,35}$ The fact that these magnesium hydroxy carbonates were not formed in substantial amounts during exposure indicates that the concentration of $\mathrm{CO}_{2}$ in the gas around the sample could have been depleted during the exposure. This is a potential drawback of the stationary experimental setup that is used in this study. Unlike in a flowing setup the composition of the gas atmosphere cannot be maintained constant. $\mathrm{CO}_{2}$ plays an important role in the atmospheric corrosion mechanism of $\mathrm{Mg}$ alloys and can decrease the corrosion rate by a factor of $6-7 .{ }^{31}$ This is explained by the formation of a protective magnesium hydroxy carbonate layer. According to Lindström et al. ${ }^{4}$ and Shahabi-Navid et al. ${ }^{31} \mathrm{CO}_{2}$ also stabilizes the surface $\mathrm{pH}$ and suppresses the dissolution of the alumina parts of the surface film. Besides, a more even, general corrosion attack is observed in the presence of $\mathrm{CO}_{2}$ whereas heavy pitting occurred without $\mathrm{CO}_{2}{ }^{4}$

Despite the drawback of $\mathrm{CO}_{2}$ depletion and a possible influence of the ORR, the new gravimetric monitoring technique offers some key advantages. Reliable corrosion rates can be monitored in realtime with a high sensitivity for the detection of small amounts of $\mathrm{H}_{2}$. Furthermore, the full corrosion kinetics can basically be obtained from one sample. Compared to mass loss, less samples are needed and the work with toxic $\mathrm{CrO}_{3}$ can be avoided. Corrosion rate monitoring is possible from the very beginning of the exposure, where mass loss measurements are difficult. On the other hand, long-term experiments with exposure times of several weeks can be realized.

Many possible applications of the new technique that rely on its non-destructive nature can be anticipated. This includes to study different exposure conditions like RH, temperature, salts or air pollutants. In addition, the effect of changes of these conditions could be followed directly on the same sample. For instance, the corrosion rate during wet and dry cycling or during temperature steps could be monitored on the same sample in real-time. This information could contribute to a better understanding of the mechanisms during accelerated testing and in real outdoor exposure. Moreover, samples with complex coating systems that cannot be studied with the mass loss technique are accessible with the gravimetric $\mathrm{H}_{2}$ technique. This includes $\mathrm{Mg}$ alloy substrates protected by conversion coatings and/or several layers of paint. The corrosion rate at defects such as scratches or stone chipping could be measured by the atmospheric $\mathrm{H}_{2}$ method. Some of these applications of the new method will be addressed in a future study. 


\section{Conclusions}

- A new gravimetric method for real-time monitoring of atmospheric $\mathrm{Mg}$ alloy corrosion rates was presented. The new method is based on measuring the buoyant force of $\mathrm{H}_{2}$ gas evolved during exposure to a humid environment with an adaption of the gravimetric setup, originally presented by Curioni. ${ }^{12}$

- The influence of temperature and atmospheric pressure variations on the measurement was examined. An effective correction to compensate for these effects was developed and reliable atmospheric $\mathrm{H}_{2}$ evolution rates could be measured.

- The new technique is non-destructive and offers a high sensitivity for the detection of small amounts of evolved $\mathrm{H}_{2}$.

- The suitability of the new method to study atmospheric $\mathrm{Mg}$ alloy corrosion was demonstrated on AZ31 and AZ91 with different levels of $\mathrm{NaCl}$ contamination. Real time monitoring of the corrosion rate is possible throughout the experiment and a good correlation of the total amount of collected $\mathrm{H}_{2}$ with mass loss was found.

- Evidence for the contribution of ORR to the cathodic processes on $\mathrm{Mg}$ alloy atmospheric corrosion was presented. The influence of ORR was found to be more significant on AZ91 compared to AZ31.

\section{Acknowledgments}

Audi AG is greatly acknowledged for the funding of the project. The authors thank Christina Hell for her help in the laboratory.

\section{ORCID}

M. Strebl (10 https://orcid.org/0000-0003-2518-4558

S. Virtanen (1D https://orcid.org/0000-0002-7179-7593

\section{References}

1. M. Esmaily, J. E. Svensson, S. Fajardo, N. Birbilis, G. S. Frankel, S. Virtanen, R. Arrabal, S. Thomas, and L. G. Johansson, Progress in Materials Science, 89, 92 (2017).

2. R. Lindström, L.-G. Johansson, and J.-E. Svensson, Materials and Corrosion, 54(8), 587 (2003).

3. M. Jönsson, D. Persson, and R. Gubner, Journal of The Electrochemical Society, 154(11), C684 (2007).

4. R. Lindström, J.-E. Svensson, and L.-G. Johansson, Journal of The Electrochemical Society, 149(4), B103 (2002).
5. ISO 8407, Corrosion of metals and alloys - Removal of corrosion products from corrosion test specimens, International Organization for Standardization (,2009).

6. T. Prosek, N. Le Bozec, and D. Thierry, Materials and Corrosion, 65(5), 448 (2014)

7. N. Van den Steen, H. Simillion, D. Thierry, H. Terryn, and J. Deconinck, Journal of The Electrochemical Society, 164(9), C554 (2017).

8. G. L. Makar and J. Kruger, Journal of The Electrochemical Society, 137(2), 414 (1990).

9. G. Baril and N. Pébère, Corrosion Science, 43(3), 471 (2001).

10. E. L. Silva, S. V. Lamaka, Di Mei, and M. L. Zheludkevich, ChemistryOpen, 7(8), 664 (2018).

11. N. T. Kirkland, N. Birbilis, and M. P. Staiger, Acta biomaterialia, 8(3), 925 (2012).

12. M. Curioni, Electrochimica Acta, 120, 284 (2014).

13. S. Fajardo and G. S. Frankel, J. Electrochem. Soc., 162(14), C693 (2015).

14. A. Wexler and S. Hasegawa, J. Res. Nat Bur. Stand., 53, 19 (1954).

15. C. F. Forney and D. G. Brandl, HortTechnology, 2(1), 52 (1992).

16. A. L. Buck, J. Appl. Meteor, 20(12), 1527 (1981).

17. H. Bettin and F. Spieweck, PTB-Mitteilungen, 100(3/90), 195 (1990).

18. F. Spieweck and H. Bettin, Technisches Messen, 59, 285 (1992).

19. L. D. Talley, Descriptive physical oceanography: an introduction, Academic press (2011).

20. D. M. Imboden and A. Wüest, in Physics and chemistry of lakes, p. 83, Springer (1995).

21. G. K. Vallis, Atmospheric and oceanic fluid dynamics, Cambridge University Press (2017).

22. L. G. Bland, A. D. King, N. Birbilis, and J. R. Scully, Corrosion, 71(2), 128 (2015).

23. ASTM G102-89, Standard Practice for Calculation of Corrosion Rates and Related Information from Electrochemical Measurements, ASTM International (2010).

24. M. Esmaily, N. Mortazavi, M. Shahabi-Navid, J. E. Svensson, M. Halvarsson, L. Nyborg, M. Wessén, A. E. W. Jarfors, and L. G. Johansson, Journal of The Electrochemical Society, 162(3), C85 (2015)

25. M. Curioni, F. Scenini, T. Monetta, and F. Bellucci, Electrochimica Acta, 166, 372 (2015).

26. Y. Yang, F. Scenini, and M. Curioni, Electrochimica Acta, 198, 174 (2016).

27. M. Esmaily, D. B. Blücher, J. E. Svensson, M. Halvarsson, and L. G. Johansson, Scripta Materialia, 115, 91 (2016).

28. M. Esmaily, J. Svensson, and L. Johansson, in Magnesium Technology 2017 , K. N. Solanki, D. Orlov, A. Singh, N. R. Neelameggham, M. Esmaily, J. E. Svensson, and L. G. Johansson, Editors, p. 397, Springer (2017).

29. O. Lunder, J. E. Lein, T. K. Aune, and K. Nisancioglu, Corrosion, 45(9), 741 (1989).

30. G. Song, A. Atrens, X. Wu, and B. Zhang, Corrosion Science, 40(10), 1769 (1998).

31. M. Shahabi-Navid, M. Esmaily, J.-E. Svensson, M. Halvarsson, L. Nyborg, Y. Cao, and L.-G. Johansson, J. Electrochem. Soc., 161(6), C277 (2014).

32. R. Sander and Henry's Law Constants, in NIST Standard Reference Database Number 69, Gaithersburg, (2018).

33. M. Kappes, M. Iannuzzi, and R. M. Carranza, J. Electrochem. Soc., 160(4), C168 (2013).

34. T. Zhang, Y. Li, and F. Wang, Corrosion Science, 48(5), 1249 (2006)

35. M. Esmaily, M. Shahabi-Navid, J.-E. Svensson, M. Halvarsson, L. Nyborg, Y. Cao, and L.-G. Johansson, Corrosion Science, 90, 420 (2015). 